\title{
Internet Filters and Academic Freedom: Librarian and Stakeholder Perceptions and Their Impact on Access to Information
}

\author{
David I. Orenstein \\ Medger Evers College \\ City University of New York, United States \\ dorenstein@mec.cuny.edu \\ Lisa Stoll-Ron \\ Warren County Community College, United States \\ lstoll@warren.edu
}

\begin{abstract}
Background. Filtering software is used in libraries to block Web-based content; this includes parts or all of certain websites, ranges of IP addresses, as well as key word level sifting of search results that delete or do not return all possible and alternative content. There are academic institutions that actively do filter access to the Internet for their students, faculty and staff.

Objective. How do librarians and other key campus stakeholders view the use of Internet filters? The data presented in this paper comes from a cross-institutional study which surveyed senior administrators, IT professionals, faculty and librarians to gauge their views related to use of Internet filters.

Methods. The data selected for this article focuses on a comparative analysis of responses to questionnaires completed by both librarians and senior administrators. However, other outcome data will be discussed for all participant groups.

Results. Results suggest that while librarians as a professional group stand firmly for open access and against filters, academic administrators are split on the role filters play in denying access to Internet content. While faculty and IT staff each view the necessity and value of filters with varying degree of approval.

Significance. These perceptions have policy implications related to academic freedom for teaching, learning and for academic libraries and IT departments, as well as their parent institutions.
\end{abstract}

\section{INTRODUCTION}

The use of Internet filters has been adopted by colleges and universities to monitor and sometimes block access to online content. While filters do play a role in eliminating content that a community finds offensive, there is no mandatory legislation requiring higher education institutions to filter content. Data was collected to understand how Internet filtering is viewed across job classifications, different campus settings and Carnegie classifications. This Carnegie system provides a framework to classify colleges and universities specific to the 
United States. The participants in the original study included college and university administrators, information technology (IT) managers, librarians and faculty from all disciplines.

Software and hardware-based filters, which sift through keywords placed in Internet search engines and online databases, work to limit the return of information from these sources. By their very purpose, filters exist to decrease the amount of information researchers can access. The impact of such filters can be found at the institutional level. Kirp (2003) related how Arcadia University (formerly known as "Beaver College") was blocked by search engines in certain public, academic and high school settings where filters blocked access to the college's website. Once the name was changed, enrollment at the university increased substantially and by the fall of 2002, "there were over five hundred freshmen, the biggest class in the school's history" (Kirp, p.14). There have been many attempts to define academic freedom over the decades. Definitions evolve over time as cultural mores and new ideas change our perceptions. For the sake of this discussion, academic freedom is defined by the authors as the fundamental human right for an individual to pursue or express knowledge and information in any venue and via any media during his or her lifetime, unencumbered by any person, policy or law which would deny such access to information.

There is significant amount of research and periodical literature related to other aspects of academic freedom. This topical research focuses on free speech, association, curriculum design, teaching methods, and the conflicted or supporting institutional and personal definitions of academic freedom in the workplace.

The use of Internet filters in higher education occurs at institutions throughout the United States. However, there appears to be no research on why colleges and universities decide to filter Internet content. There are no codified lists noting the total number of colleges or universities in the United States that filter Internet content. A review of higher educational listservs, association Web sites and college specific Internet access policies found that there are public and private, as well as large and small, institutions representing many states and Carnegie classifications that actively use, plan to implement, or have removed Internet filtering software. These include, but are not limited to, institutions in Pennsylvania, Oregon, Virginia, Tennessee, North Carolina, Arizona, New Jersey, Texas, North Dakota, Ohio, Washington State and Iowa.

There are no federal or state laws that explicitly require denial of access software; therefore, the decision to block content and implement filters is based on the values of those who control access to online resources. However, federal laws such as the Digital Millennium Copyright Act of 1998 and its updates, as well as the Higher Education Act of 2008, all place restrictions on access to copyrighted works without authorization or password protection via peer-to-peer networks. This can cause higher education institutions and their leadership to seek legal guidance related to online access and academic freedom.

The perception that filters are required so that they limit access to content, image or video assumes that the information is unworthy of access, not reliable, illegally acquired, useless for research, or it may appear to be offensive in some way to the morals or other standards set by the college community. However, such perceptions may inhibit research needs, violate American Association of University Professors (AAUP) standards and reverse federal guarantees provided through the Constitution's First Amendment regarding free speech and freedom of the press.

By understanding these stakeholders' perceptions, colleges and universities assess the value staff and faculty place on filters versus open access. Such understanding could help administrators plan for the use of a widening array of information technology that 
incorporates the Internet for the creation and management of data as well as access to information for teachers, researchers and administrators.

A filter's purpose is to block incoming information to computers by removing access to Web-based search results or access to whole Web sites. Filters become active when computer administrators place specific keywords, phrases, concepts, website URLs or IP addresses into software that blocks access to content over the Internet. Those involved in the process of implementing and managing a filtering policy may focus on negative aspects of the Internet in its current "Wild, Wild West" incarnation, perceiving the unregulated medium as void of any editorial controls. As noted by Maich (2006), "The idealists who conceived and pioneered the Web described it as a kind of enlightened utopia ... Instead, we have constructed a virtual wild west, where the masses indulge their darkest voices [and] pirates troll for victims" (p. 45). Since there are no reviewers or content editors, anyone can write or upload anything they wish to the World Wide Web. From a research perspective this means that unless a computer or network uses filters to block content, researchers have unlimited access to written ideas, or sounds and images that could be used for study and alternatively be deemed "offensive" by a community. Therefore, the perceptions of academic leaders and other stakeholders who implement filtering on their campuses should be better understood.

The importance of the Internet as a delivery medium for information and communication has been well documented. The Internet has changed higher education by speeding up communication and the sharing of information. It has also changed pedagogic delivery by creating accessible learning through distance education and by promoting opportunities to research through faster and more robust databases.

\section{LITERATURE REVIEW AND BACKGROND}

Filters do serve a positive purpose when they block offensive content such as hardcore pornography or other adult-themed materials and websites not intended for children. Legislation such as Child Internet Protection Act (2000) impacts elementary schools and public libraries, where community standards and federal legislation may impose strict standards for the agencies to receive monies to provide educational or informational services. Such federal regulation does not enforce content filters in higher education; therefore, the decision to filter is one made internally, at the institutional level.

However, when a higher education institution implements an information policy that uses filtering technology, they are potentially adding electronic barriers to information, which may then lead to violations of AAUP policies related to academic freedom and access to research. In addition, such a policy may negatively impact academic freedom and also the First Amendment right to freely research. Because no research exists, this study was directed to find possible relationships between stakeholder perceptions of information access and the implementation of filtering technology. This study has value for planning and policy makers as well as faculty who conduct research and use the Internet for pedagogy. The use of Internet filters is not just an issue for faculty and administrators working in colleges and universities. In the United States, the First Amendment right to free speech, access to information and free expression, are all vital for the continuation of our democracy. In fact, open access to information is considered by the United Nations to be a fundamental civil right. Article 19 of the United Nations (2012) Charter on Human Rights specifically addresses free and open access to information. The Charter states, "Everyone has the right to freedom of opinion and expression; this right includes freedom to hold opinions without interference and to seek, receive and impart information and ideas through any media and regardless of frontiers." 
Both the AAUP and the American Library Association (ALA) support open and unfettered access to information, regardless of modality for students and faculty involved in the academic enterprise. The American Association of University Professors (2008) states, "Teachers are entitled to full freedom in research and in the publication of the results ... [and this] applies with no less force to the use of electronic media for the conduct of research and the dissemination of findings and results." The American Library Association (2000) statement notes, "The American Library Association affirms that the use of filtering software by libraries to block access to constitutionally protected speech violates the Library Bill of Rights.”

As reported by Davis (2001) regarding the AAUP Council endorsement of ACRL's Intellectual Freedom Principles for Academic Libraries, "Academic freedom is indispensable for ensuring the availability of information and ideas...so that teacher may freely teach and students may freely learn" (p. 5). Filtering of Internet and online content may violate this intellectual freedom and through the review of institutional policy and stakeholder perceptions regarding when and why filters are used, we may gain an understanding of possible relationships between institutions that filter online content and those that do not filter online information.

The original study employed a mixed methods approach and participants were selected based on their job classification and include academic deans, IT administrators holding CIO, VP or Director titles, librarians and teaching faculty from the humanities, the arts, social and physical sciences. Survey participants came from a total of 11 Carnegie classed institutions. These institutions include three public associate degree-granting colleges, two public baccalaureate degree-granting colleges, one public and one private master degree-granting universities, one public and one private doctorate degree-granting universities, and two private special focus institutions. Since the authors are employed and reside in the New York area, all colleges and universities used for this study are located in the northeastern portion of the United States.

Prior to the 1940 statement on research access and its successive reinterpretations, the AAUP had supported academic freedom through its 1915 Declaration of Principles. Included in those principles were the core philosophical tenets that would ultimately establish the modern professoriate and its relation to institutions of higher learning. According to Pecorino (2006), those tenets upheld three main domains of action, including "freedom of inquiry and research, freedom to teach, and freedom with extramural utterances" (p. 2). Each of these domains supported what was considered the common good. So, a professor who could teach, speak, and research freely was seen as a cornerstone to the development of both faculty and the students who would come to institutions of higher learning.

If the original tenets of academic freedom, as postulated in the 1915 Principles sought to connect the public good with the methods and responsibilities of the "professorial class," then the later Statement by the AAUP worked to solidify faculty and their pursuit of research and academic freedom as a partner in democracy. Metzger (1955) noted that the original tenets focused on three requirements, "the need for academic research, adequate instruction, and the development of experts for public service" (p. 134). Each of these tenets forecasted later trends related to the explosion of information and access, the development of teaching methods and the need to have faculty serve society through the personal and specialized expertise.

Supportive organizations, including academic libraries 30 years before the AAUP's codified statement held that access to research was one of the library's core reasons for being (Dain, 1990; Hamlin, 1981). As noted by Sutton's (2001) ACRL conference presentation, 
"Because a library, any library, is first and foremost a place to access information, the principle of intellectual freedom becomes central to the mission of our profession" (p. 54).

Codified statements of principles do help support academics in performing research and pedagogy. Institutional stakeholders who subjectively find specific information objectionable have challenged academic freedom and these objections can confront open access. Internet filters are just the latest and newest form of blocking such access to information. Objections can come from trustees, college management, faculty, parents, community members, as well as governmental agencies. Moshman (1994) rhetorically asked, "is [academic freedom] freedom to teach ... to learn ... to engage in original research? Academic freedom involves all of the above" (p. 26). Therefore, it is the role of those involved in academia to understand and react, write open access policies and take action to support academic freedom with the help and support of college administration to avoid censorship.

It is an understatement to say that the Internet and the resulting World Wide Web has had a significant impact on higher education. With the Internet, access to information, online learning and the richness of databases that provide and foster communication over time and distance emboldens the academic enterprise. If the Internet were absent from the lives of students, faculty and institutions, the rate of change and of the exchange of ideas, concepts and understanding would be reduced, as the pursuit of knowledge and research would move at a much slower place.

While the Internet democratizes access to the formulation of and the sharing of information, it is important to remember that not everything found on the World Wide Web is wholly accurate. Researchers must remember that the truthfulness, accuracy, timeliness and unbiased nature of online information should be reviewed with the same critical standards that print and other research is encountered. According to Orenstein (2008), "these very issues make information literacy and critical thinking an important element of teaching researchers how best to understand and interpret the nature of data in the Age of Information."

Gurak and Duin (2004) noted that the Internet as a digital technology for teaching and research has created enhancements to technical communication. The authors note, "The impact of the Internet and digital technologies on teaching and research...has resulted in increased access and expectations, scholarship and community building, accountability, and partnering on the part of students, faculty and out programs" (p. 188). This democratization brings with it many positives but also several stresses for those charged with planning for technological change. These stresses include forecasting trends, budgeting and ensuring that communication technology and training keeps up with the pace of change.

From the view of those who use libraries and other academic sources to enliven or improve their lives, it is apparent that students, as part of the general public, see the unfettered and open Internet as a lifeline to perform research and develop skills necessary to live in our digital world. According to the Institute of Museum and Library Services (2008), the agency found

When adults seek information to make decisions or solve problems they use such sources as persons, books, newspapers, magazines, the Internet and television. When information is needed, the most frequently used source is the Internet (33\%) followed by other persons (29\%), books (14\%), newspapers and magazines $(10 \%)$ and other sources $(14 \%)$. (p. 26$)$

So while the Internet has been around in its current form for little more than a decade, according to IMLS data, it serves as the first place that people go to, to look for and find information. 
The popularity of the Internet as a research tool also comes across in other studies that attempt to understand the impact ubiquitous access to online and digital information has on researchers and the institutions that service their education and information needs. Everhart and Valenza (2004) note that researchers from the Pew Research Foundation found three trends in how students view their work. First, the authors note, "Most students [78\%] prefer to use the Internet to perform research," second, "these students felt their faculty needed more training on how to use the Web to create assignments" and third, "the students were frustrated by limitations and filtering of Internet access [where it was occurring]" (p. 53). These trends appear to show that students view themselves as having superior Internet search skills and feel they are savvy researchers, despite believing their faculty and institutions as having less sophistication or level of access that match the students' desire.

\section{RESEARCH METHOD}

The purpose of the original study was to gain insight into the perceptions key academic stakeholders hold regarding Internet filters. A mixed-methods study explored the perceptions of stakeholders employed at 14 Carnegie-classified institutions related to the use of Internet filters and their potential impact on academic freedom. The study participants were each given a 15-question questionnaire employing the Likert scale. Selected participants were also interviewed using a set of 10 open-ended questions to obtain more detailed responses. A total of 22 interviews and 154 completed questionnaires were collected from the participants. This paper focuses on the data collected from the questionnaires using the Likert scale, and compares responses specifically between librarians and academic administrators, which constitute almost half of the survey and questionnaire results.

Using the multi-method approach can be an asset to overcome the problem of methodboundedness (Cohen \& Manion, 1994). Therefore, it can be surmised that by interviewing administrators regarding their perceptions of academic freedom as well as the use of Internet filters, and presenting them with a Likert-based survey on those same variables, this study could show a relationship based on their responses to the questions presented in the study.

Each question and potential response on the Likert scale was coded. The coded questions were transferred into a spreadsheet using Microsoft Excel and then downloaded into the statistical software, SPSS, for analysis. This process converted the raw data into statistics to confirm, compare or contrast both the Likert and questionnaire survey results. The data compared and contrasted responses from individuals at 14 Carnegie classed institutions. Additionally, the data was analyzed to gain an understanding of the perceptions administrators, faculty, IT managers and librarians hold regarding Internet filtering. These perceptions were also analyzed to see if they support or diverge from current filtering practices at the participant's institution of employment.

Upon receipt of the survey data, these statistics were counted to validate or disprove the null hypothesis. In his discussion of reporting research data, Babbie (1990) noted, "All aspects of the analysis should be described in sufficient detail to permit a secondary analysis to replicate the analysis from the same body of data" (p. 334). Therefore, by both implication and current standards, a discussion of the results culled from the resultant analysis and set of conclusions along with recommendations for further study serve to complete the research design. 
Table 1. Question 2: Blocking access to the Internet is ok

\begin{tabular}{ccccc}
\hline Choice & Administrator & $\mathrm{n}$ & Librarian & $\mathrm{n}$ \\
\hline 1 & 9.1 & 2 & 72.1 & 24 \\
2 & 27.1 & 6 & 27.2 & 9 \\
3 & 18.2 & 4 & 0.0 & 0 \\
4 & 36.4 & 8 & 0.0 & 0 \\
5 & 9.1 & 2 & 0.0 & 0 \\
\hline
\end{tabular}

\section{RESULTS}

Of the 14 schools originally selected for the study, 11 colleges and universities offered their institution as hosts for the research. One school rejected the solicitation to participate, while two schools could not convene their Institutional Review Board committees or could not provide a response within the timeframe of the study's deployment. Thus $78.5 \%$ of the schools that were asked to participate agreed providing a good representation of a variety of Carnegie classified institutions discussed in the research design.

Had all schools agreed to host the research, the total pool of participants would have been 196 individuals. Of the institutions that did participate, all 154 participants completely filled out the survey forms. Within this group, 22 senior administrators were asked to participate in answering additional interview questions that took about 45 minutes. All of the participating administrators responded to each interview question. The completed surveys and interviews represent 11 of 14 possible institutions or a $73 \%$ response rate.

Participants were asked to complete a fifteen-question survey form using the Likert scale. For the sake of data review and to allow for discussion and further discovery, this article looks to compare six of the fifteen questions for analyses. It should be noted that results from the other questions not included in this paper also compare equally for statistical value and variance, but because of space considerations, the charts and discussion for this section focus on those results that reflect the theme and focus of the data from the study herewith.

The six questions focus on different issues and areas for information gathering and sharing and include access (Question 2); restriction and suppression of information (Question 8); internal policy (Question 11), perceptions regarding personal and institutional support Internet research statements posted by third party professional organizations (Questions 13 and 14) and external laws and their impact on internal policy development (Question 15). More specifically, the inquiry looked at blocking Internet access and the resulting need to locate information; perceptions regarding censorship; institutional response in maintaining the academic enterprise; personal views and perceptions of how AAUP and ALA is supported with regard to academic freedom, and finally a response to the question of whether state and federal government policy should set Internet access policies in higher education.

In Table 1, administrators and librarians were asked if Internet filters which block access to websites are ok, even if they deny needed content since students could find information from other sources. In this study "choice one" indicates strong disagreement with the statement. Where "choice three" indicates somewhat in agreement and finally "choice five" indicates strong agreement with the statement presented. 
Table 2a. Question 8: Filters equal censorship and should be avoided

\begin{tabular}{ccccc}
\hline Choice & Administrator & $\mathrm{n}$ & Librarian & $\mathrm{n}$ \\
\hline 1 & 13.6 & 3 & 0.0 & 0 \\
2 & 22.7 & 5 & 0.0 & 0 \\
3 & 9.1 & 2 & 0.0 & 0 \\
4 & 27.3 & 6 & 6.1 & 9 \\
5 & 27.3 & 6 & 93.9 & 31 \\
\hline
\end{tabular}

Table 2b. Results of significance test for the difference between the two groups for Question 8

\begin{tabular}{|c|c|c|c|c|c|c|}
\hline $\begin{array}{c}\text { Levene's Test For } \\
\text { Equality of } \\
\text { Variance }\end{array}$ & \multicolumn{5}{|c|}{ t-test for equality of means } \\
\hline $\mathrm{F}$ & Sig. & $\mathrm{t}$ & $\mathrm{df}$ & Sig. (2-tailed) & Mean Difference & $\begin{array}{c}\text { Std. error } \\
\text { Difference }\end{array}$ \\
\hline 3.559 & .074 & -2.710 & 20 & .013 & 1.91667 & .70735 \\
\hline
\end{tabular}

The data suggest that while librarians as a constituent group overwhelmingly chose response one or two, totaling $100 \%$, the administrators surveyed took a more nuanced view of the question. As noted in the table, $36 \%$ of administrators disagreed with the statement. While $18 \%$ were somewhat in agreement and $45 \%$ agreed with the statement that blocking access to the Internet was ok. This indicates that while librarians disapprove of making researchers go elsewhere to find information, only a third of the surveyed administrators had a similar sentiment, and about half the administrators had the opposite sentiment.

The survey statement reflected in the responses in Table 2a asks a direct two-part question. The first states that blocking access is tantamount to censorship, while the second part of the question states that online censorship should not occur on college and university campuses.

In response to this question, librarians perceived the issue to mean filters equal censorship and that blocking access via filtering is not what institutions of higher learning should be doing. The librarian group overwhelmingly (100\%) agreed that filtering is censorship and that colleges and universities should avoid censorship through these means. The administrators surveyed showed that 55\% percent agreed with the statement, while more than a third $(36.3 \%)$ of these participants strongly or mildly disagreed that blocking access is censoring, or that institutions should not block access through filtering content.

It is important to note that the differences in administrator responses to this question can be directly related to the filtering policies at their parent institutions. Administrators employed by institutions that did not use filters were more likely to choose Option 3 (somewhat agree) or greater on the Likert scale, indicating that filtering is a form of censorship and it should not be allowed on college and university campuses. Administrators from institutions that employed filters were more likely to disagree with the statement in this Likert question, indicating their agreement with censorship and its application through Internet filters at the college and university levels. The difference in responses based on the filtering policies of the institution is statistically significant, as noted in Table $2 \mathrm{~b}$. 
In Table 3a, respondents were asked if filters that over block access to non-offensive online content should be removed if they deny access to valuable research. Results indicated that all of the librarians $(100 \%)$ strongly agreed or agreed with the statement. However, administrators surveyed agreed at a rate of slightly more than half (55\%) strongly agreed or agreed with the statement and $32 \%$ strongly disagreed or disagreed with the question.

Similar to the previous question, there is a statistically significant difference in administrator responses based on the filtering policies of their parent institution, as noted in Table 3b. Administrators employed by institutions that do not employ Internet filters were more likely to "somewhat agree" to "strongly agree" that over-blocked non-offensive content should be removed because it could potentially deny access to valuable research. Conversely, administrators employed by institutions that do utilize Internet filters were more likely to "somewhat disagree" to "disagree" (Likert options 2 and 1) with the statement.

The next series of questions asked if individual respondents agree with AAUP and ALA written policies regarding the free and open access to research online materials. Respondents were given copies of the policy statements to review prior to completing the survey. The second question asked if the respondents believed that their institutions supported the same AAUP and ALA access policy statements.

As Table 4 shows, personal support of AAUP and ALA policies is very strong amongst librarian respondents. One hundred percent of the librarians surveyed strongly agreed or agreed with the statement. Administrators had a high rate of agreement to this question as well. Slightly more than two-thirds or $68 \%$ of the administrators responding to this question agreed, while 22.7 somewhat agreed and $9 \%$ disagreed with the statement.

Table 5 indicates the perceived institutional support of AAUP and ALA open access policies by the surveyed stakeholders. $94 \%$ of librarians perceived that their institution accepts and supports the AAUP/ALA statements; while $72 \%$ of administrators affirmed this perception of their institution.

In the last set of responses to the final question on the survey reflected in Table 6, survey participants were asked their view of authorizing and extending intervention into campus policy related to online filtering. The question asks if federal and/or state laws requiring Internet filters in public places such as K-12 and public libraries should be extended to higher education. The table shows responses that indicate almost universal disagreement with the question. One hundred percent of the librarians and $72 \%$ of the administrators surveyed disagreed with the question. However, $27 \%$ of the administrators surveyed, somewhat or on some other level agreed that there should be some external legal intervention.

This paper pares down the original data collection to allow the authors to focus on administrator and librarian perceptions concerning Internet filtering. We believe it is also important to note a few details regarding the other two groups who participated in the research, namely teaching faculty and IT professionals. Such data will be fully detailed in later papers. However we do wish to share three tidbits of information that shed light on the perception of filters across all four groups surveyed. First, the data from the surveys showed that IT professionals and academic administrators that work at Institutions that do use blocking mechanisms to parse Internet content are 50\% less likely to perceive such policies as a form of censorship than those same professionals working at institutions which do not such block full access. Secondly, at schools that do deny access to Internet content, the decision to implement such policies and install such devices and/or software are evenly split between IT professionals and Dean-level or above in terms of administrative responsibility. Thirdly, there was a high correlation between teaching faculty and librarians regarding their non-support of 
Table 3a. Question 11: Institutions should not over-block access

\begin{tabular}{ccccc}
\hline Choice & Administrator & $\mathrm{n}$ & Librarian & $\mathrm{n}$ \\
\hline 1 & 13.6 & 3 & 0.0 & 0 \\
2 & 18.2 & 4 & 0.0 & 0 \\
3 & 13.6 & 3 & 0.0 & 0 \\
4 & 36.4 & 8 & 27.3 & 9 \\
5 & 18.2 & 4 & 72.7 & 24 \\
\hline
\end{tabular}

Table 3b Results of significance test for the difference between the two groups for Question 11

\begin{tabular}{|c|c|c|c|c|c|c|}
\hline $\begin{array}{c}\text { Levene's Test } \\
\text { for Equality of } \\
\text { Variance }\end{array}$ & \multicolumn{6}{|c|}{ t-test for Equality of Means } \\
\hline $\mathrm{F}$ & Sig & $\mathrm{t}$ & $\mathrm{df}$ & Sig. (2-tailed) & Mean Difference & $\begin{array}{c}\text { Std. error } \\
\text { Difference }\end{array}$ \\
\hline 2.3159 & .144 & -2.896 & 20 & .009 & 1.8611 & .64259 \\
\hline
\end{tabular}

Table 4. I support AAUP and ALA open access policies

\begin{tabular}{ccccc}
\hline Choice & Administrator & $\mathrm{n}$ & Librarian & $\mathrm{n}$ \\
\hline 1 & 0.0 & 0 & 0.0 & 0 \\
2 & 9.1 & 2 & 0.0 & 0 \\
3 & 22.7 & 5 & 0.0 & 0 \\
4 & 36.4 & 8 & 30.3 & 10 \\
5 & 31.8 & 7 & 69.7 & 23 \\
\hline
\end{tabular}

Table 5. My institution supports AAUP and ALA open access policies

\begin{tabular}{ccccc}
\hline Choice & Administrator & $\mathrm{n}$ & Librarian & $\mathrm{n}$ \\
\hline 1 & 0.0 & 0 & 0.0 & 0 \\
2 & 9.1 & 2 & 0.0 & 0 \\
3 & 18.2 & 4 & 0.0 & 0 \\
4 & 50.0 & 11 & 66.7 & 22 \\
5 & 22.7 & 5 & 27.2 & 9 \\
\hline
\end{tabular}

Table 6. Local and federal government laws should regulate Internet access in higher education settings

\begin{tabular}{ccccc}
\hline Choice & Administrator & $\mathrm{n}$ & Librarian & $\mathrm{n}$ \\
\hline 1 & 68.2 & 15 & 93.9 & 31 \\
2 & 4.5 & 1 & 6.1 & 2 \\
3 & 4.5 & 1 & 0.0 & 0 \\
4 & 18.2 & 4 & 0.0 & 0 \\
5 & 4.5 & 1 & 0.0 & 0 \\
\hline
\end{tabular}


implementing Internet filters on their campus. The perception of filters as being a negative held true for librarians and teaching faculty who worked on campuses that filter and did not filter access to Web-based content.

\section{CONCLUSION}

It is clear from research presented in this paper that certain long-established trends in perception and allied working models of service regarding open access emerge based on the responses to the survey data. It can be said with statistical authority that librarian participants as a demographic group in all Carnegie classed institutions and filtering settings firmly do not support content filtering of Internet access.

However, academic administrators are split on the use of content filters based in all of the questions presented in this paper. Current filtering policy of the institution clearly impacts the perceptions of the administrators and their motivation to influence policy impacting the use of Internet filters. As a result, institutional filtering policies may also impact their perceptions of academic freedom. Because academic freedom includes "full freedom in research," administrators or institutions in agreement with policies that deny access to information via Internet filters and censorship are also denying students and faculty the right to complete academic freedom (Orenstein, 2009). It is conjecture to assume motivation and perception without other content information, but perceptions are typically influenced by an institution's current filtering policy, personal knowledge and interest of the issues related to censorship in general and online censorship more specifically, academic freedom and the use and ubiquity of the Internet as an information delivery system.

Where both administrators and librarians greatly agreed was in the area of autonomy and control of academic policy, neither group believed that local or national laws should be enacted to require higher education institutions to install content-based Internet filters. Those surveyed believed that such access policies are individual campus' decisions and that the choice to filter or not filter is one based on campus culture and community involvement. Both librarians and academic administrators believed that they personally support AAUP and ALA related to open access to online content. However, when both groups were asked if they felt their institution supported these same policies, administrators were less likely to strongly agree with that question. On the other hand, librarians felt their colleges and universities were in compliance with these external policies. The survey questions did not ask and the data could not show why there is such a split in perception, so it unknown why a schism exists in relation to these perceptions.

Additionally, librarians as a group were in lock-step agreement either strongly for questions which asked if censorship or other blocking of content was wrong and should be avoided in higher education settings, or strongly for questions which dealt with maintenance of free and open access to Internet information. While administrators were more nuanced and were only mildly for or against Internet controls or even perceiving blocking software as censorship. These results could certainly be based on current ALA policies, professional training and the personal attitude of librarians as a professional group as each support full and open access to information regardless of type or modality.

As there is a paucity of information on the use and impact of Internet filters in higher education institutions, it is the hope of the researchers of this study that the data provided, even if it constitutes a first step and "slice in time" research that the end-product of this study will be valuable for librarians and other academic decision makers. It would be unlikely that changes in policy would occur without some level of literature search to serve as a basis for 
discussion and perhaps later action; therefore, this research can be of value to stakeholders who review campus policies to defend against filtering and equally for those who institute, manage or use such filtering technology on their campus.

\section{REFERENCES}

American Association of University Professors. (2008). Academic freedom and electronic communication. Retrieved from http://www.aaup.org/AAUP/pubsres/policydocs/contents/electcomm-stmt.htm

American Library Association. (2000). Statement on library use of filtering software. Retrieved from http://www.ala.org/Template.cfm?Section=IF_Resolutions\&Template=/ContentManag ement/ContentDisplay.cfm\&ContentID $=13090$

Babbie, E. (1990). Survey research methodology (2nd ed.). Belmont, CA: Wadsworth. Child Internet Protection Act, 47 U.S.C. $§ 231$ (2000).

Cohen, L., \& Manion, L. (1994). Research methods in education (4th ed.). London: Routledge.

Dain, P. (1990). Scholarship, higher education, and libraries in the United States: Historical questions and quests. In J. Y. Cole. (Ed.), Libraries and scholarly communication in the United States: The historical dimension. New York: Greenwood Press.

Davis, M.E. (2001). AAUP endorses ACRL statement on intellectual freedom. College and Research Library News, 62(1), 5-8.

Digital Millennium Copyright Act of 1998, § 17 U.S.C. § 101 (1998).

Evahart, N., \& Valenza, J.K. (2004). Internet savvy students and their school. Knowledge Quest, 32(4), 50-55.

Gurak, L.J., \& Duin, A.H. (2004). The impact of the Internet on digital technologies on teaching and research in technical communication. Technical Communication Quarterly, 13(2), 187-188.

Hamlin, A.T. (1981).The university library in the United States: Its origins and development. Philadelphia: University of Pennsylvania Press.

Higher Education Act of 2008, 20 U.S.C.S. § 1001 (2008).

Institute of Museum and Library Services. (2008). Interconnections: The ILMS national study on the use of libraries, museums and the Internet (IMLS document). Washington, DC: Author.

Kirp, J.L. (2001). Shakespeare, Einstein and the bottom line: The marketing of higher education. Cambridge, MA: Harvard University Press.

Maich, S. (2006). Pornography, gambling, lies, theft and terrorism: The Internet sucks (Where did we go wrong?). Maclean's, 119(43), 44-49.

Metzger, W.P. (1955). Academic freedom in the age of the university. New York: Columbia University Press.

Moshman, D. (1994). Academic freedom: Student rights and faculty responsibilities. In J. E. Brown (ed.), Preserving intellectual freedom: Fighting censorship in our schools (pp.26-35). Urbana, IL: National Council of Teachers of English.

Orenstein, D.I. (2008). Restructuring information literacy for the 21st century community college. Washington, NJ: Warren County Community College.

Orenstein, D.I. (2009). Filtering access to Internet content at higher education institutions: Stakeholder perceptions and their impact on research and academic freedom (Doctoral 
dissertation, Capella University, Minneapolis). Available from ProQuest Dissertations $\&$ Theses database. (ProQuest Document ID 305166345, Order No. 3378420)

Pecorino, P.A. (2006). Academic freedom and CUNY: An argument for the creation of a faculty committee on academic freedom. Retrieved from http://www.qcc.cuny.edu/SocialSciences/ppecorino/Academic-Freedom-Need-forcom.html

Sutton, L. (2001). Advocacy for intellectual freedom in an academic library. In Crossing the Divide: Proceedings of the ACRL 10th National Conference (pp. 54-56). Retrieved from http://www.ala.org/acrl/sites/ala.org.acrl/files/content/conferences/pdf/sutton.pdf United Nations. (2012, March). The universal declaration of human rights. Retrieved from http://www.un.org/en/documents/udhr/index.shtml 